\title{
Critérios de legalidade constitucional para a função normativa do Conselho Nacional de Justiça: o exemplo do direito de família
}

\author{
Criteria of constitutional legality for the normative function of the National Council \\ of Justice: the example of family law
}

\author{
Caroline Pomjé* \\ Simone Tassinari Cardoso Fleischmann ${ }^{* *}$
}

\section{Resumo}

O presente estudo aborda - por meio do método indutivo e dos procedimentos de pesquisa bibliográfica, pesquisa jurisprudencial e de estudo de caso - a problemática envolvendo a expedição de normativas pelo Conselho Nacional de Justiça que impliquem, ainda que indiretamente, a regulação do exercício de direitos pelos sujeitos em suas relações interprivadas. Visando à construção de uma leitura que possibilite a compatibilização entre as competências do CNJ, a densificação das normas constitucionais no ambiente privado e o exercício de direitos fundamentais pelos sujeitos familiares, este artigo propõe critérios para o controle da atividade regulamentar do CNJ no Direito de Família.

Palavras-chave: Conselho Nacional de Justiça. Família. Legalidade constitucional. Autonomia privada. Intervenção estatal.

\section{Abstract}

The present study approaches - through the inductive method and procedure of bibliographic research, jurisprudential research and case study - the problematic involving the issuance of regulations by the National Council of Justice that imply, although indirectly, the regulation of the exercise of rights by the subjects in their private relations. Aiming at constructing a reading that makes possible the compatibility of the competencies of the NCJ, the densification of constitutional norms in the private ambience and the exercise of fundamental rights by family subjects, this article proposes criteria for the control of the regulatory activity of the NCJ in Family Law.

Keywords: National Council of Justice. Family. Constitutional Legality. Private autonomy. State intervention.

\section{Introdução}

A pluralidade de fontes normativas presentes no ordenamento jurídico nacional submete-se à unidade axiológica decorrente das normas constitucionais (TEPEDINO, 2008, p. 362). No âmbito do Direito de Família, a Constituição assume posição de fonte principal na medida em que estabelece, nos arts. 226 e 227, regras e princípios referentes à sua estruturação (FARIAS; ROSENVALD, 2018, p. 57). O Código Civil e leis esparsas, assim, detêm papel secundário, devendo ser interpretados, sempre, à luz das normativas constitucionais.

Ocorre que, recentemente, o Conselho Nacional de Justiça (CNJ) tem assumido função relevante na expedição de diretivas referentes à organização familiar. Considerando o incremento da busca pela resolução extrajudicial de conflitos e a competência do referido Conselho para a formulação de normas voltadas à fiscalização dos sistemas notarial e registral (MAFFINI, 2015, p. 03), ${ }^{1}$ tem-se que o CNJ vem, paulatinamente, assumindo uma postura regulatória em questões de Direito de Família.

Mestre em Direito Privado na Universidade Federal do Rio Grande do Sul. Advogada. Porto Alegre -RS- Brasil. E-mail: carol.pomje@gmail.com. Doutora e Mestre em Direito pela PUCRS. Professora do Programa de Mestrado e Doutorado em Direito da Universidade Federal do Rio Grande do Sul. Porto Alegre - RS - Brasil. E-mail: sitassinari@hotmail.com.

Importa destacar, desde logo, a diferenciação existente entre o sistema notarial e o sistema registral no que condiz, especialmente, com as atribuições de seus membros: "[...] o notário extrai a vontade negocial das partes, reduzindo-a a termo, instrumentalizando-a e autenticando-a, para que possa valer para o futuro, e pode fazer tudo o que a lei não proíbe (princípio da autonomia privada dos usuários), enquanto o registrador, destinatário dos atos praticados pelos notários, examina a validade destes, para que possa atribuir a publicidade erga omnes e os efeitos deles esperado. E submete-se ao bloqueio de legitimação, ou seja, só faz o que a lei autoriza (princípio da legalidade)". (KÜMPEL, 2019, p.). 
As atividades de registrais e notariais são reguladas pela Lei $n .{ }^{\circ} 8.935$, de 18 de novembro de 1994, que concretiza o art. 236 da Constituição Federal de 1988. Compete ao CNJ a expedição de atos administrativos que contenham "determinações e instruções que a Corregedoria ou os tribunais expedem para a regularização e uniformização dos serviços, especialmente os da Justiça, com o objetivo de evitar erros e omissões na observância da lei" (MEIRELLES; BURLE FILHO, 2016, p. 210). O exercício dessa atividade de regulação e uniformização dos serviços de justiça ocorre por meio de resoluções e provimentos. Trata-se de atos administrativos que não se confundem: enquanto os provimentos caracterizam-se pelo fato de serem atos administrativos que contêm "determinações e instruções que a Corregedoria ou os tribunais expedem para a regularização e uniformização dos serviços, especialmente os da Justiça, com o objetivo de evitar erros e omissões na observância da lei" (MEIRELES; BURLE FILHO, 2016, p. 210), as resoluções:

[...] são atos administrativos normativos expedidos pelas altas autoridades do Executivo (mas não pelo Chefe do Executivo, que só deve expedir decretos) ou pelos presidentes de tribunais, órgãos legislativos e colegiados administrativos, para disciplinar matéria de sua competência específica. Por exceção admitem-se resoluções individuais.

As resoluções, normativas ou individuais, são sempre atos inferiores ao regulamento e ao regimento, não podendo inová-los ou contrariá-los, mas unicamente complementá-los e explicá-los. Seus efeitos podem ser internos ou externos, conforme o campo de atuação da norma ou os destinatários da providência concreta (MEIRELES; BURLE FILHO, 2016, p. 208).

A partir da análise pontual do art. 103-B da CRFB/88, depreende-se a competência regulamentar do Conselho Nacional de Justiça, na medida em que a ele cabe "o controle da atuação administrativa e financeira do Poder Judiciário e do cumprimento dos deveres funcionais dos juízes" (art. 103-B, §4", CRFB/88). Além disso, o inciso I estabelece a necessidade de zelo "pela autonomia do Poder Judiciário e pelo cumprimento do Estatuto da Magistratura, podendo expedir atos regulamentares, no âmbito de sua competência, ou recomendar providências" (art. 103-B, inciso I, CRFB/88).

Seguindo a mesma tendência, o Regimento Interno do Conselho Nacional de Justiça, em seu art. $8^{\circ}$, estabelece como atribuição do Corregedor Nacional de Justiça a expedição de atos normativos voltados "ao aperfeiçoamento das atividades dos órgãos do Poder Judiciário e de seus serviços auxiliares e dos serviços notariais e de registro, bem como dos demais órgãos correcionais, sobre a matéria relacionada com a competência da Corregedoria Nacional de Justiça". Além disso, o Regulamento Geral da Corregedoria Nacional de Justiça, em seu art. 14, ao elencar as modalidades de atos que podem vir a ser expedidos pelo Corregedor-Geral de Justiça, estabelece que o provimento representa "ato de caráter normativo interno e externo com a finalidade de esclarecer e orientar a execução dos serviços judiciais e extrajudiciais em geral”.

Depreende-se, assim, que compete ao Conselho Nacional de Justiça - para além da função regulamentar prevista na Constituição - a fiscalização efetiva das atividades notarial e registral (KÜMPEL; BORGARELLI, 2018, p. 01). Só no ano de 2017 foram expedidos seis provimentos que impactaram diretamente nos sistemas notarial e registral, abordando questões atinentes, por exemplo, à cobrança emolumentar, ao procedimento de usucapião extrajudicial e ao reconhecimento e averbação de paternidade e maternidade socioafetivas (KÜMPEL; BORGARELLI, 2018, p. 01).

Nesse ambiente, as questões que se impõem e que são enfrentadas por meio do presente estudo podem ser do seguinte modo elencadas:

(i) Em que medida, e sob quais critérios, é possível a efetiva imposição de normas ${ }^{2}$ pelo $\mathrm{CNJ}$ aptas a atingir particulares no ambiente do Direito Privado?

(ii) Seria o CNJ competente para expedir normas voltadas ao(à) cidadão(ã) comum?

(iii) Quais os limites à atuação normativa do CNJ?

(iv) Qual a força cogente das eventuais normativas expedidas pelo CNJ?

Compreendidas como "regulações capazes de obrigar", no sentido de permissões, vedações ou concessões. 
Para responder a tais perguntas é necessário discutir se, em um ambiente de legalidade constitucional materialmente considerado, é possível afirmar a constitucionalidade do Órgão, a sua capacidade para expedição de normas, o caráter de originariedade ou de derivação para as normas expedidas, e, por fim, se já se pode afirmar a existência de critérios de validação para o conteúdo por elas densificado.

Com a finalidade de responder às perguntas acima elencadas, o estudo utiliza-se do método indutivo, partindo da análise de determinadas fontes de informação (decisões judiciais, textos legislativos e normativas expedidas pelo Conselho Nacional de Justiça), com o objetivo de, a partir dessas fontes, extrair critérios para o controle da atividade regulamentar realizada pelo CNJ. Considerando as divisões metodológicas apresentadas por Denise Tolfo Silveira e Fernanda Peixoto Córdova (2009, p. 31-42), pode-se afirmar que, quanto à abordagem, esta pesquisa pode ser caracterizada como quali-quantitativa, posto que faz uso concomitante da pesquisa qualitativa (para interpretação de documentos normativos) e da pesquisa quantitativa (para verificação de recorrência da utilização de resoluções e provimentos em decisões jurisprudenciais nos Tribunais de Justiça nacionais).

Quanto à sua natureza, trata-se de pesquisa aplicada, voltada à resolução de problema específico, referente à estipulação de critérios para controle da atuação normativa do Conselho Nacional de Justiça. No que tange aos seus objetivos, a pesquisa é, ao mesmo tempo, exploratória e descritiva, visando à explicitação dos problemas envolvendo a atividade regulamentar do CNJ e à descrição e análise dos fatos que envolvem esses problemas. Por fim, quanto aos procedimentos, trata-se de pesquisa bibliográfica, jurisprudencial e de estudo de caso, considerando a análise dos diferentes provimentos e resoluções exarados pelo Conselho em matéria de Direito de Família.

\section{Premissas básicas para a construção da legalidade constitucional da atuação normativa do $\mathrm{CNJ}$ nas relações interprivadas}

Para que seja viabilizada a análise acerca da constitucionalidade da atuação normativa do Conselho Nacional de Justiça no âmbito das relações interprivadas, faz-se necessário prévio estudo acerca do posicionamento do Supremo Tribunal Federal sobre a questão. O referido Tribunal foi instado a se manifestar acerca da atuação do CNJ em duas diferentes oportunidades: a primeira, por meio da Ação Direta de Inconstitucionalidade n. ${ }^{\circ}$ 3367-1/DF; a segunda, por meio da Ação Declaratória de Constitucionalidade n. ${ }^{\circ}$ 12. Passa-se à análise pormenorizada.

\subsection{Da constitucionalidade do Conselho Nacional de Justiça}

O Supremo Tribunal Federal, instado a se manifestar acerca da constitucionalidade do Conselho Nacional de Justiça no âmbito da Ação Direta de Inconstitucionalidade n. ${ }^{\circ} 3367-1 / D F$, movida pela Associação dos Magistrados Brasileiros (AMB), reconheceu a constitucionalidade do Conselho, haja vista a preservação da separação e da independência entre os Poderes. Com efeito, a referida ADI voltava-se contra os arts. $1^{\circ}$ e $2^{\circ}$ da Emenda Constitucional n. ${ }^{\circ} 45 / 2004$, e tinha como causa de pedir supostas violações ao princípio da separação e da independência dos poderes, bem como ofensa ao pacto federativo (BRASIL. ADI 3.367-1/DF, 2006, p. 203). Dessa maneira, como o Conselho Nacional de Justiça seria voltado "ao 'controle da atuação administrativa e financeira' do Judiciário e do 'cumprimento dos deveres funcionais' dos magistrados" ao mesmo tempo em que seria "composto por membros na origem alheios ao mesmo Poder", alegava-se a violação à cláusula pétrea de separação dos poderes (BRASIL. ADI n. ${ }^{\circ} 3.367-1 / D F, 2006$, p. 208).

O ministro relator Cezar Peluso destacou que a estrutura institucional dos Poderes foi desenhada pelo constituinte com a garantia de independência para o exercício das funções típicas de cada Poder. Assim, essa independência seria mitigada a partir da presença de outras "atribuições, muitas das quais de controle recíproco, e cujo conjunto forma, com as regras primárias, verdadeiro sistema de integração e cooperação, preordenado a assegurar equilíbrio dinâmico entre os órgãos" (BRASIL. ADI n. ${ }^{\circ} 3.367-1 / D F, 2006$, p. 221-222). No mesmo sentido, o ministro Eros Grau posicionou-se fazendo referência à "inquestionável constitucionalidade" da fiscalização e do controle exercidos pelo Conselho Nacional de Justiça, cabendo a tal 
órgão, unicamente, "o controle da atuação administrativa e financeira do poder Judiciário e do cumprimento dos deveres funcionais dos juízes" (BRASIL. ADI n. ${ }^{\circ} 3.367-1 / D F, 2006$, p. 282).

Consequentemente, afastada a inconstitucionalidade do Conselho Nacional de Justiça pela ausência de violação ao princípio da separação dos poderes, fixou-se o entendimento pela "subsistência do núcleo político do princípio, mediante preservação da função jurisdicional, típica do Judiciário, e das condições materiais do seu exercício imparcial e independente" (BRASIL. ADI n. ${ }^{\circ} 3.367-1 / D F, 2006$, p. 197).

Ocorre que, três anos após o julgamento da ADI n. ${ }^{\circ}$ 3367-1/DF - realizado em abril de 2005 -, o Supremo Tribunal Federal deparou-se novamente com questionamentos acerca da constitucionalidade da atuação do Conselho Nacional de Justiça.

A Ação Declaratória de Constitucionalidade n. ${ }^{12}$, da Associação dos Magistrados Brasileiros (AMB), requereu o reconhecimento da legitimidade da Resolução n. ${ }^{\circ}$ 07/2005 do Conselho Nacional de Justiça, que "disciplina o exercício de cargos, empregos e de servidores investidos em cargos de direção e assessoramento, no âmbito dos órgãos do Poder Judiciário e dá outras providências". Na prática, a supramencionada resolução ensejou a vedação à prática de nepotismo por meio da impossibilidade de que cônjuges, companheiros e parentes de magistrados fossem empregados em tribunais caso não fossem aprovados em concurso público.

Houve, portanto, um segundo grau de questionamento sobre constitucionalidade: enquanto o primeiro operou-se a partir de questionamentos acerca da constitucionalidade do próprio órgão, o segundo teve por objeto resolução específica exarada pelo CNJ, que, enquanto ente, já havia sido considerado constitucionalmente legítimo.

\subsection{Da capacidade do Conselho Nacional de Justiça para expedição de normas e o caráter de primariedade reconhecido pelo Supremo Tribunal Federal}

Uma dúvida em voz corrente trazida em sucessivas oportunidades em salas de aula e eventos acadêmicos diz respeito à qualidade democrática e constitucional do órgão - diferente do Poder Executivo para normatizar. Para além das questões sobre a judicialização da política e da função normativa do próprio Poder Judiciário, ${ }^{3}$ identifica-se como órgão máximo responsável por reconhecer caráter de normatividade o próprio Supremo Tribunal Federal.

A habilitação ou não do Conselho Nacional de Justiça para a expedição de normas foi levada à discussão perante o STF a partir dos questionamentos da ADC n. ${ }^{\circ} 12$ e houve pronunciamento meritório. Naquela oportunidade, além de afirmar a possibilidade de expedição normativa, também foram qualificadas tais normas. Portanto, aos que questionam a legitimação democrática e constitucional do CNJ para normatizar, ressalte-se que já há pronunciamento do Supremo Tribunal Federal que reconhece competência normativa do Conselho Nacional de Justiça. ${ }^{4}$

No julgamento da $A D C$ n. ${ }^{\circ} 12$, o ministro relator Carlos Ayres Britto reiterou a ausência de violação ao princípio da separação dos Poderes e ao princípio federativo (BRASIL. ADC n. ${ }^{\circ}$ 12/DF, 2009, p. 02); enquanto isso, o ministro Menezes Direito destacou a competência do Conselho Nacional de Justiça para densificar os princípios constantes na Constituição "no que tange ao poder administrativo que detém no âmbito do Poder Judiciário" (BRASIL. ADC n. ${ }^{\circ}$ 12/DF, 2009, p. 15). Ocorre que o pronunciamento do STF também qualificou as normas exaradas pelo $\mathrm{CNJ}$ como normas primárias, o que trouxe consequências significativas no ordenamento jurídico.

Quando da análise da medida liminar requerida na $\operatorname{ADC} n .^{\circ} 12$, o ministro relator consignou a diferenciação entre atos normativos primários e secundários - inserindo as resoluções exaradas pelo CNJ na primeira espécie -, bem como destacou a possibilidade de inovação jurídica por intermédio de atos normativos primários:

Sobre ativismo judicial ver: Trindade e Morais (2011, p. 137-54).

Importa ressaltar que a legitimidade do STF para esse reconhecimento não está sendo levantada neste trabalho, uma vez que a legitimidade constitucional desse órgão é imanente de suas funções precípuas. 
Já no plano da autoqualificação do ato do CNJ como entidade jurídica primária, permito-me apenas lembrar, ainda nesta passagem, que o Estado-legislador é detentor de duas caracterizadas vontades normativas: uma é primária, outra é derivada. A vontade primária é assim designada por se seguir imediatamente à vontade da própria Constituição, sem outra base de validade que não seja a Constituição mesma. Por isso que imediatamente inovadora do Ordenamento Jurídico, sabido que a Constituição não é diploma normativo destinado a tal inovação, mas à própria fundação desse Ordenamento. Já a segunda tipologia de vontade estatal-normativa, vontade tão somente secundária, ela é assim chamada pelo fato de buscar o seu fundamento de validade em norma intercalar; ou seja, vontade que adota como esteio de validade um diploma jurídico já editado, este sim, com base na Constituição. Logo, vontade que não tem aquela força de inovar o Ordenamento com imediatidade (BRASIL. Medida Cautelar na ADC n² 12-6/DF, 2006, p. 19).

As resoluções do Conselho Nacional de Justiça - assim como as resoluções do Senado Federal, as medidas provisórias, os decretos e os regimentos internos dos tribunais - seriam atos normativos primários, podendo, portanto, "inovar no ordenamento jurídico independentemente da existência de interposto texto legal" (NOGUEIRA, 2006) - cabendo lembrar, aqui, a qualificação das resoluções como sendo atos normativos voltados a disciplinar matéria de competência exclusiva (MEIRELLES; BURLE FILHO, 2016, p. 208).

Dessa forma, verifica-se que, ao menos em duas oportunidades, o Supremo Tribunal Federal fixou o entendimento pela ausência de violação à separação dos Poderes e ao princípio federativo pela atuação do Conselho Nacional de Justiça. Cabe ao CNJ, assim, além de regularizar e uniformizar os serviços por meio de provimentos, disciplinar matérias integrantes de sua competência através de resoluções.

Do exposto até aqui, assentou-se a competência regulamentar do Conselho Nacional de Justiça, prevista constitucionalmente (art. 103-B, $\S 4^{\circ}$ e inciso I, CRFB/88), bem como a competência para a expedição de normativas voltadas ao aperfeiçoamento dos serviços notariais e de registro (art. $8^{\circ}$ do Regimento Interno do $\mathrm{CNJ}$ ) e voltadas ao esclarecimento e à orientação da execução dos serviços judiciais e extrajudiciais em geral (art. 14 do Regulamento Geral do CNJ). A competência do Conselho Nacional de Justiça para a expedição de resoluções, dentro de sua competência e provimentos, voltadas à padronização das atividades notarial e registral, portanto, é cabal.

A referida competência do Conselho Nacional de Justiça para a expedição de normativas voltadas aos sistemas notarial e registral, no entanto, não representa total liberdade nessa regulamentação, conforme seguinte posicionamento doutrinário:

No Estado Democrático de Direito, é inconcebível permitir-se a um órgão administrativo expedir atos (resoluções, decretos, portarias, etc) com força de lei, cujos reflexos possam avançar sobre direitos fundamentais, circunstância que faz com que tais atos sejam ao mesmo tempo legislativos e executivos, isto é, como bem lembra Canotilho, a um só tempo 'leis e execução de leis' (STRECK; SARLET; CLÈVE, 2006, p. 02, grifo original).

Consequentemente, seguindo o entendimento de supramencionados autores, o Conselho Nacional de Justiça enfrentaria duas modalidades de limitação na edição de atos regulamentares: "uma, stricto sensu, pela qual não podem expedir regulamentos com caráter geral e abstrato, em face da reserva de lei; outra, lato sensu, que diz respeito à impossibilidade de ingerência nos direitos e garantias fundamentais dos cidadãos" (STRECK; SARLET; CLĖVE, 2006, p. 03). Destaca-se, por oportuno, que a reserva de lei - ou princípio da legalidade - representa "uma peça essencial do Estado de direito", objetivando outorgar uma "garantia ao cidadão contra o arbítrio do administrador" (SOARES, 1981, p. 169).

Apesar dos méritos do entendimento acima apresentado, tem-se que o Supremo Tribunal Federal, ao consignar que as normativas expedidas pelo CNJ correspondem a atos normativos primários (BRASIL. Medida Cautelar na ADC n. $\left.{ }^{0} 12-6 / D F, 2006\right)$, autorizou a expedição de atos com caráter geral e abstrato, no caso da ADC n. ${ }^{\circ} 12$, dentro da competência constitucionalmente prevista. Assim, haveria a possibilidade de o Conselho Nacional de Justiça emitir normativas com caráter geral e abstrato desde que estribadas em sua competência constitucional, devendo buscar parâmetros de conformação no próprio texto constitucional.

Por outro lado, quando diante de matéria em que há fonte normativa prévia, entende-se que a questão objeto de análise pelo Conselho Nacional de Justiça deve ser regulada com base na fonte, sem 
inovação - até porque, nessa hipótese, o Poder Legislativo já teve a oportunidade de exercer sua atribuição regulando a matéria (hipótese em que o Poder Legislativo exerceu sua atribuição típica). Dessa maneira, a atuação do Conselho Nacional de Justiça seria unicamente no sentido de fornecer mais subsídios materiais e axiologicamente orientados à aplicação da fonte prévia.

Deve ser objeto de apreciação, por fim, a hipótese em que a atuação do CNJ avança sobre temática que ainda não foi objeto de deliberação legislativa - ou sequer de manifestação com caráter vinculante por parte do Poder Judiciário. Em tal situação excepcional, não havendo fonte normativa prévia, e, em respeito à posição do STF, que o reconhece como órgão passível desse ato, defende-se que a atuação do Conselho deve se dar no atendimento da axiologia constitucional, como critério material de legitimação e validação. Assim, não seriam permitidos atos normativos tendentes à redução ou mitigação de direitos e garantias fundamentais, tampouco os que invertessem a lógica da principiologia constitucional.

\section{Dos critérios para a verificação da legitimidade constitucional das normativas expedidas pelo Conselho Nacional de Justiça}

Do conteúdo apresentado até o momento, as seguintes conclusões parciais podem ser sinteticamente apresentadas:

a. O Conselho Nacional de Justiça é órgão constitucional, conforme entendimento fixado no julgamento da ADI n. ${ }^{\circ} 3367-1 /$ DF pelo STF;

b. É competência do CNJ a expedição de normas (resoluções e provimentos) voltadas a regulamentar as atividades notarial e registral, na forma do art. $8^{\circ}$ do Regimento Interno do Conselho Nacional de Justiça; e

c. As resoluções exaradas pelo CNJ têm caráter de primariedade e, com isso, estariam autorizadas a inovar na Ordem Jurídica, conforme entendimento do ministro relator Carlos Britto no julgamento da Medida Cautelar na ADC n. ${ }^{\circ} 12-6 / D F$.

A conclusão parcial elencada no item "a" apresenta-se como premissa básica para o presente estudo, sendo elemento a partir do qual se sustentam as considerações que seguem. No que tange à conclusão parcial apresentada no item "b", é interessante destacar que o fato de o Conselho Nacional de Justiça possuir competência para a expedição de normativas voltadas à regulamentação das atividades notarial e registral enseja, ainda que indiretamente, a imposição de normas aptas a atingir particulares no ambiente do Direito Privado. Consequentemente, tem-se a imposição de normas pelo CNJ aptas a influenciar o exercício de direitos pelos sujeitos, em suas esferas de autodeterminação, tal qual questionado no ponto "i" da introdução do presente estudo.

Assim, pode-se afirmar que, ainda que o Conselho Nacional de Justiça não proceda à normatização direta de questões envolvendo interesses particulares, procede à criação de possibilidades ou limitações ao exercício de direitos pelos indivíduos. A título de exemplo, a Resolução n. ${ }^{\circ}$ 175, de 14 de maio de 2013, dispõe sobre a possibilidade de "habilitação, celebração de casamento civil, ou de conversão de união estável em casamento, entre pessoas de mesmo sexo", representando, portanto, a regulamentação sobre a viabilidade de exercício de um direito personalíssimo por determinadas pessoas. Seguindo a tendência de regulamentar o exercício de direitos personalíssimos, o Provimento n. $^{\circ} 63$, de 14 de novembro de 2017 , recentemente alterado pelo Provimento n. ${ }^{\circ} 83$, de 14 de agosto de 2019, trata "sobre o reconhecimento voluntário e a averbação da paternidade e maternidade socioafetiva no Livro ' $A$ ' e sobre o registro de nascimento e emissão da respectiva certidão dos filhos havidos por reprodução assistida". No âmbito desse mesmo provimento, porém, encontrava-se interessante limitação ao exercício de direitos pelos particulares: embora fosse reconhecida a viabilidade de reconhecimento de paternidade ou maternidade socioafetiva, o art. 14 do Provimento n. ${ }^{\circ}$ 63/2017 afirmava que "o reconhecimento da paternidade ou maternidade socioafetiva somente poderá ser realizado de forma unilateral e não implicará o registro de mais de dois pais ou de duas mães no campo FILIAÇÃo no assento de nascimento" (grifamos).

A partir da vigência do Provimento n. ${ }^{\circ} 83 / 2019$, o art. 14 do Provimento $n .^{\circ} 63 / 2017$ passou a vigorar acrescido de dois parágrafos: o primeiro, afirmando que "somente é permita a inclusão de um ascendente 
socioafetivo, seja do lado paterno ou do materno"; o segundo, dispondo que "a inclusão de mais de um ascendente socioafetivo deverá tramitar pela via judicial". Logo, verifica-se, pelo menos a priori, a manutenção de uma limitação ao número de pais ou mães que podem figurar no campo filiação do assento de nascimento, o que consiste em uma limitação ao exercício de direitos pelos indivíduos.

No que concerne à conclusão parcial "c", de acordo com a qual as normas exaradas pelo CNJ têm caráter de primariedade e, com isso, estariam autorizadas a inovar na ordem jurídica, importa destacar que eventual inovação no ordenamento jurídico nacional deve estar vinculada à própria atividade do Conselho Nacional de Justiça, podendo ser vislumbradas duas situações distintas. A primeira quando há fonte normativa prévia (assim considerada a existência de uma lei ou de uma decisão judicial em caráter vinculante tratando acerca da temática) e a segunda quando não há fonte normativa prévia, de modo que a manifestação pelo próprio CNJ seria o marco inicial da discussão sobre aquele tema.

Inicialmente, em havendo fonte normativa prévia (legal ou jurisprudencial), a atividade do Conselho Nacional de Justiça voltada à regulamentação das atividades notarial e registral envolvendo aquela temática deve estar vinculada a essa fonte. Isso ocorre porque, como já indicado anteriormente, nessa situação, o Poder Legislativo (em se tratando de lei prévia) ou o Poder Judiciário (em se tratando de decisão jurisprudencial em caráter vinculante) já tiveram a oportunidade de exercer suas respectivas atribuições acerca da matéria. Dessa maneira, reitera-se que a atuação do Conselho Nacional de Justiça seria unicamente no sentido de fornecer mais subsídios materiais e axiologicamente orientados à aplicação da fonte prévia.

A fim de exemplificar a hipótese acima exposta, convém referir quais as fontes normativas prévias à edição dos principais Provimentos e Resoluções em matéria de Direito de Família pelo CNJ. A Resolução n. ${ }^{\circ} 35 / 2007$ foi editada com o objetivo de uniformizar as medidas quanto à aplicação da Lei $n .^{\circ} 11.441 / 2007$ em território nacional, de modo que referida legislação apresenta-se como a fonte normativa prévia. A Resolução n. ${ }^{\circ}$ 175/2013, por sua vez, não contava com legislação prévia à sua edição pelo Conselho Nacional de Justiça: da leitura de referida Resolução extrai-se que seu embasamento é realizado pelo CNJ a partir dos acórdãos prolatados em julgamento da ADPF n. ${ }^{\circ}$ 132/RJ e da ADI n. ${ }^{\circ} 4277 / D F$, que reconheceram "a inconstitucionalidade de distinção de tratamento legal às uniões estáveis constituídas por pessoas de mesmo sexo", bem como do julgamento do REsp n. ${ }^{\circ} 1.183 .378 / R S$, por meio do qual o STJ "decidiu inexistir óbices legais à celebração de casamento entre pessoas do mesmo sexo".

Apesar de a Resolução n. ${ }^{\circ} 175$ evidentemente representar um avanço em termos de garantias fundamentais - o que se coaduna com a impossibilidade de as normativas do Conselho Nacional de Justiça violarem direitos fundamentais -, verifica-se que a "fonte normativa" prévia existente na situação concreta era representada por decisões do Supremo Tribunal Federal e do Superior Tribunal de Justiça. Diante desse cenário, o Partido Social Cristão ajuizou o Mandado de Segurança Coletivo n. ${ }^{0} 32.077$, sustentando que a edição da Resolução n. ${ }^{\circ}$ 175/2013 teria "violado o direito líquido e certo de seus membros e afiliados ao devido processo legislativo constitucional" (BRASIL. Medida Cautelar no MS n. ${ }^{\circ} 32.077 / D F, ~ 2013$, p. 03). Em seu voto, o ministro relator Luiz Fux destacou o caráter geral e abstrato da Resolução n. ${ }^{\circ} 175 / 2013$, a qual ancorou sua disciplina diretamente nos preceitos constitucionais:

De fato, a referida Resolução, à semelhança das espécies normativas primárias, retira seu fundamento de validade diretamente da Lei Fundamental, e não de outro ato normativo que a tenha precedido. Em seus consideranda, a Resolução CNJ n 175/2013 claramente alude ao seu fundamento: as decisões proferidas por esta Suprema Corte, nos autos da ADPF n 132/RJ e da ADI n 4277/DF, ambas de relatoria do Min. Ayres Britto, e a decisão proferida nos autos do REsp n 1.183.378/RS, Rel. Min. Luis Felipe Salomão. Em todos os casos, a controvérsia gravitou em torno do sentido e alcance da exegese do art. $226, \S^{\circ}$, da Constituição da República. É inobjetável, diante dessa constatação, que a Resolução n 175/2013, por buscar seu fundamento de validade no art. 226, §3º, da CRFB/88, na interpretação que Ihe foi conferida pelo Supremo Tribunal Federal e pelo Superior Tribunal de Justiça, reveste-se de generalidade, autonomia, abstração e impessoalidade. Exatamente porque ostenta tais apanágios, a Resolução n 175/2013 qualifica-se como 'lei em tese', razão por que não se submete ao controle jurisdicional pela via do mandado de segurança (BRASIL. Medida Cautelar no $M S n^{\circ} 32.077 / D F, 2013$, p. 06). 
Ainda, destacou que, quando do julgamento da ACD n. ${ }^{\circ} 12$, o Supremo Tribunal Federal consignou "expressamente a competência do Conselho Nacional de Justiça para editar atos normativos primários" (BRASIL. Medida Cautelar no MS n 32.077/DF, 2013, p. 07), de modo que restaria "firmada a premissa de que o Conselho Nacional de Justiça pode inovar na ordem jurídica" (BRASIL. Medida Cautelar no MS $n^{\circ}$ 32.077/DF, 2013, p. 12).

A mesma questão envolvendo a ausência de lei prévia foi enfrentada pelo CNJ quando da expedição do Provimento n. ${ }^{\circ}$ 63/2017: nesse caso, os considerandos do Provimento são expressos ao trazer como fundamento para a normativa "a ampla aceitação doutrinária e jurisprudencial da paternidade e maternidade socioafetiva, contemplando os princípios da afetividade e da dignidade da pessoa humana como fundamento da filiação civil" (grifamos), além de julgamentos do Supremo Tribunal Federal (RE n. ${ }^{\circ}$ 898.060/SC, ADPF $n^{\circ}$ 132/RJ e ADI n 4.277/DF) e do Superior Tribunal de Justiça (REsp n. ${ }^{\circ} 1.183 .378 / R S$ ).

Por fim, apesar de não se enquadrar como um tema unicamente de Direito de Famílias, o Provimento n. ${ }^{\circ} 67$, de 26 de março de 2018, também merece um olhar atento no presente estudo. O referido provimento "dispõe sobre os procedimentos de conciliação e de mediação nos serviços notariais e de registro do Brasil", de modo que, ainda que indiretamente, é aplicável à resolução de conflitos familiares, sendo que a fonte normativa prévia à sua expedição corresponde à Lei n. ${ }^{0} 13.140$, de 26 de junho de 2015.

Por outro lado, em se tratando de questão sobre a qual ainda não houve manifestação do Poder Legislativo ou do Poder Judiciário, o presente estudo baseia-se na necessidade de que o Conselho Nacional de Justiça assuma postura voltada à concretização dos direitos fundamentais constitucionalmente previstos, especialmente diante do entendimento de que as fontes normativas primárias são assim designadas por se seguirem "imediatamente à vontade da própria Constituição, sem outra base de validade que não seja a Constituição mesma" (BRASIL, Medida Cautelar na ADC n. ${ }^{\circ}$ 12-6/DF, 2006, p. 19). Valores como a dignidade da pessoa humana, igualdade, liberdade e resguardo da autonomia privada dos sujeitos, portanto, deveriam pautar a atuação do CNJ quando da regulamentação de questões envolvendo temáticas inovadoras.

Apesar de, até o momento, a maior parte dos provimentos e resoluções exarados pelo CNJ possuir fonte normativa prévia (seja lei, seja decisão judicial em caráter vinculante), como visto anteriormente, no ano de 2018, a questão atinente à possibilidade de lavratura de escrituras públicas de uniões poliafetivas foi objeto de apreciação pelo Conselho, por meio do Pedido de Providências n. ${ }^{\circ}$ 0001459-08.2016.2.00.0000, requerimento formulado pela Associação de Direito de Família e das Sucessões (ADFAS), e decidido pelo Conselho Nacional de Justiça em junho de 2018.

De acordo com o relatório de lavra do ministro João Otávio de Noronha, corregedor nacional de Justiça, o pedido de providências foi formulado em face do $3^{\circ}$ Tabelião de Notas e Protesto de Letras e Títulos de São Vicente (SP) e do Tabelião de Notas e de Protesto de Letras e Títulos da Comarca de Tupã (SP), os quais teriam lavrado "escrituras de 'união poliafetiva' consubstanciada na 'união estável' constituída entre três ou mais pessoas reciprocamente", ato que, de acordo com o requerente, seria inconstitucional "tendo em vista a falta de eficácia jurídica e violação a) dos princípios familiares básicos; $b$ ) das regras constitucionais sobre família; c) da dignidade da pessoa humana; d) das leis civis; e e) da moral e dos costumes brasileiros".

A questão levada à apreciação do Conselho Nacional de Justiça, enquanto órgão competente para tanto, foi em relação à (im)possibilidade de tabelionatos lavrarem escrituras públicas contendo declaração de união poliafetiva. Diante da absoluta inexistência de fonte normativa anterior - pois a irresignação da Associação de Direito de Família e das Sucessões adveio da situação fática de terem sido lavradas escrituras públicas de relacionamentos poliafetivos -, tem-se que o entendimento do Conselho Nacional de Justiça encaminhou-se para a manutenção de um estado de coisas que não se coaduna com a realidade social de muitas famílias. Houve, assim, injustificada limitação da autonomia privada e da liberdade de formação familiar, especialmente se considerarmos a família como um lócus de desenvolvimento humano que não possui um interesse "superior e superindividual" (PERLINGIERI, 2002, p. 243).

As dificuldades de defesa da tese adotada pelo Conselho Nacional de Justiça para rechaçar a possibilidade de lavratura de escrituras públicas de uniões poliafetivas restam evidentes, também, quando 
se verifica o teor declaratório inerente às escrituras públicas. Como destaca Brandelli (2009, p. 345), "não há tipicidade nas possibilidades de escrituras. Há tantas escrituras possíveis quantas forem as possibilidades da vontade das partes em matéria de atos jurídicos". Assim, em sendo vontade das partes declarar a existência de uma união poliafetiva para que produza os efeitos jurídicos necessários, poderia o Poder Público negar-se a tal lavratura? Não residiria, nessa impossibilidade, uma violação à dignidade daqueles que compõem, faticamente (para além do mundo do direito!) aquela unidade familiar? Não seria necessário tutelar de maneira adequada os interesses daqueles que formaram uma família diferente dos padrões a que, contemporaneamente, a sociedade brasileira encontra-se majoritariamente adaptada?

Parece que, com o reconhecimento da possibilidade de lavraturas de escrituras públicas declarando a existência de um relacionamento poliafetivo, e com a consequente atribuição de efeitos jurídicos futuros a essa declaração, estar-se-ia tutelando, materialmente, a dignidade daqueles que compõem o núcleo familiar, através de uma visão aberta e includente, no sentido do entendimento de que "para a concretização do princípio da dignidade da pessoa humana, há necessidade de uma visão aberta e includente, para além dos dispositivos codificados, de modo a garantir a tutela jurídico ao ser humano, no seu sentido ontológico" (CARDOSO, 2004, p. 90).

A partir dessas considerações, o seguinte quadro esquemático pode ser apresentado:

Quadro 01: Esquematização das conclusões parciais do estudo

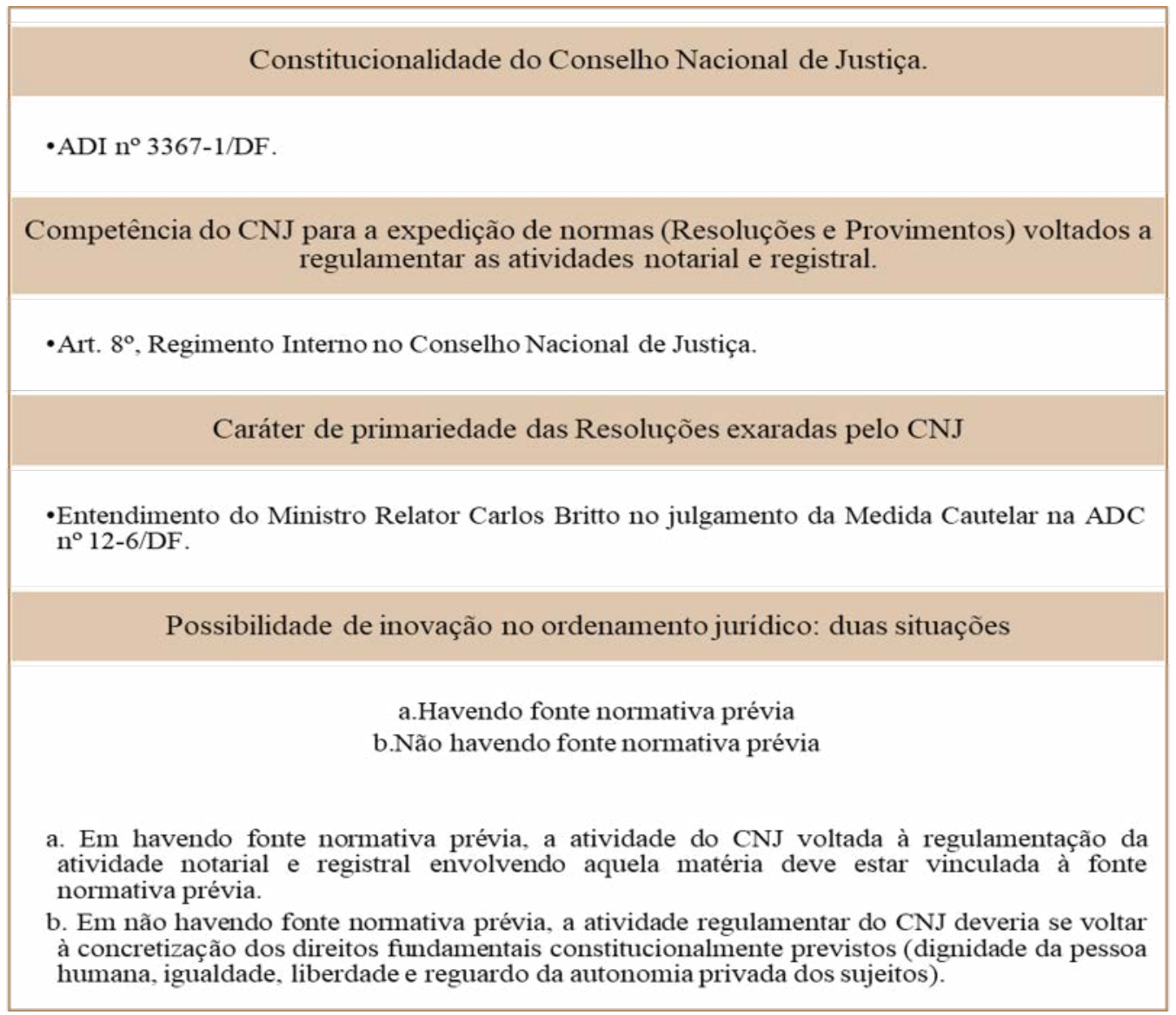

Fonte: elaborado pelas pesquisadoras

Considerando a segunda pergunta elencada no início do presente artigo, ${ }^{5}$ pode-se afirmar a competência - ainda que indireta - para que o CNJ expeça normas voltadas à regulação do exercício de direitos pelos cidadãos comuns, uma vez que, por meio da regulamentação das atividades notarial e registral, o referido órgão acaba atingindo o exercício dos direitos pelos particulares.

5 “(ii) Seria o CNJ competente para gerar normas para o(a) cidadão(ã) comum?”. 
Por outro lado, diante da terceira pergunta apresentada, ${ }^{6}$ depreende-se que dois diferentes limites podem ser elencados quanto à atuação normativa do Conselho, diferenciando sua aplicação conforme exista ou não fonte normativa prévia regulando a matéria objeto de apreciação pelo órgão. Primeiro, havendo lei ou decisão jurisprudencial prévia, a regulamentação das atividades notarial e registral realizada pelo CNJ deve ser balizada pelas diretivas oriundas do Poder Legislativo ou do Poder Judiciário, as quais presumidamente já procederam à densificação dos comandos constitucionais. Por outro lado, não havendo fonte normativa prévia, a atividade regulamentar do Conselho Nacional de Justiça deve ser pautada pelo resguardo da dignidade, da liberdade, da igualdade e da autonomia privada dos indivíduos, como forma de densificação de preceitos constitucionais voltados à construção da legalidade constitucional nas relações interprivadas.

No que se refere, por fim, ao quarto questionamento apresentado na introdução do presente artigo, ${ }^{7}$ verifica-se a possibilidade de sua análise por meio de pesquisa jurisprudencial. Assim, considerando a necessidade de que se verifique qual a força cogente das normativas expedidas pelo CNJ em matéria de Direito de Família - ou seja, se tais normativas vêm sendo aplicadas no âmbito das relações interprivadas -, procedeu-se à realização de pesquisa jurisprudencial em Tribunais de Justiça de vinte e seis estados da federação, bem como do Distrito Federal, visando à localização de decisões judiciais que remetessem à aplicação direta dos comandos constantes em resoluções e provimentos do CNJ. A pesquisa, de caráter quantitativo, foi realizada entre os dias 24 e 27 de junho de 2019, junto aos repositórios digitais dos Tribunais de Justiça brasileiros.

Em relação à Resolução n. ${ }^{\circ} 35$, de 24 de abril de 2007, a pesquisa visando à verificação de sua aplicação no âmbito do Poder Judiciário utilizou como critérios de busca as palavraschave "Resolução $n .^{\circ}$ 35 " e "CNJ". Excluídos os resultados que não versavam sobre a aplicação da normativa ora estudada, a seguinte quantidade de acórdãos remetendo à aplicação da Resolução foi encontrada:

Gráfico 01: Aplicação da resolução N. ${ }^{\circ} 35$, do CNJ, pelos Tribunais de Justiça

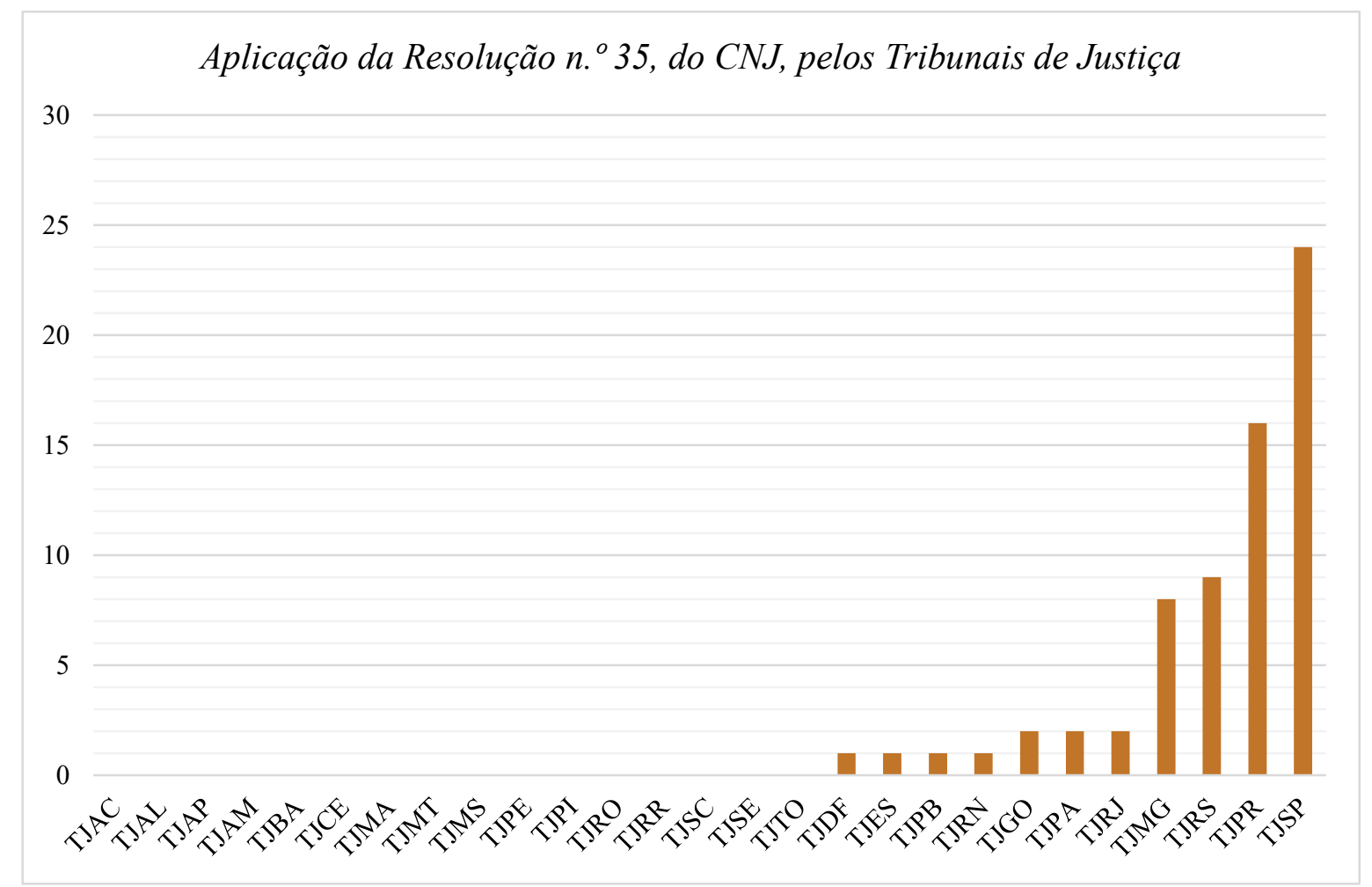

Fonte: elaborado pelas pesquisadoras

"(iii) Quais os limites à atuação normativa do CNJ?".

"(iv) Qual a força cogente das eventuais normativas expedidas pelo CNJ?".

Exceto nas buscas efetuadas no Tribunal de Justiça do Estado da Bahia e no Tribunal de Justiça do Estado do Tocantins, uma vez que nesses Tribunais procedeu-se a um maior refinamento da busca, incluindo-se a palavra-chave "divórcio". 
Verifica-se, a partir da coleta de dados realizada junto aos repositórios de jurisprudência mantidos pelos Tribunais de Justiça do país, que em ao menos sessenta e sete oportunidades ${ }^{9}$ o Poder Judiciário, em segunda instância, aplicou a Resolução $n .^{\circ} 35$, do $\mathrm{CNJ}$ como forma de auxiliar no julgamento de questões envolvendo a aplicação da Lei . $^{\circ} 11.441 / 2007$, o que indica um dos modos pelos quais as normativas expedidas pelo Conselho Nacional de Justiça acabam afetando os sujeitos privados.

Com relação à aplicação da Resolução n. ${ }^{\circ} 175$, de 14 de maio de 2013, por sua vez, a pesquisa, visando à verificação de sua aplicação no âmbito do Poder Judiciário, utilizou como critérios de busca as palavras-chave "Resolução $n .{ }^{\circ} 175^{\prime}$ e "CN ${ }^{\prime} .{ }^{10}$ Excluídos os resultados que não versavam sobre a aplicação da normativa ora estudada, a seguinte quantidade de acórdãos remetendo à aplicação da resolução foi encontrada nos Tribunais de Justiça brasileiros:

Gráfico 02: Aplicação da resolução N. ${ }^{0} 175$, do CNJ, pelos Tribunais de Justiça

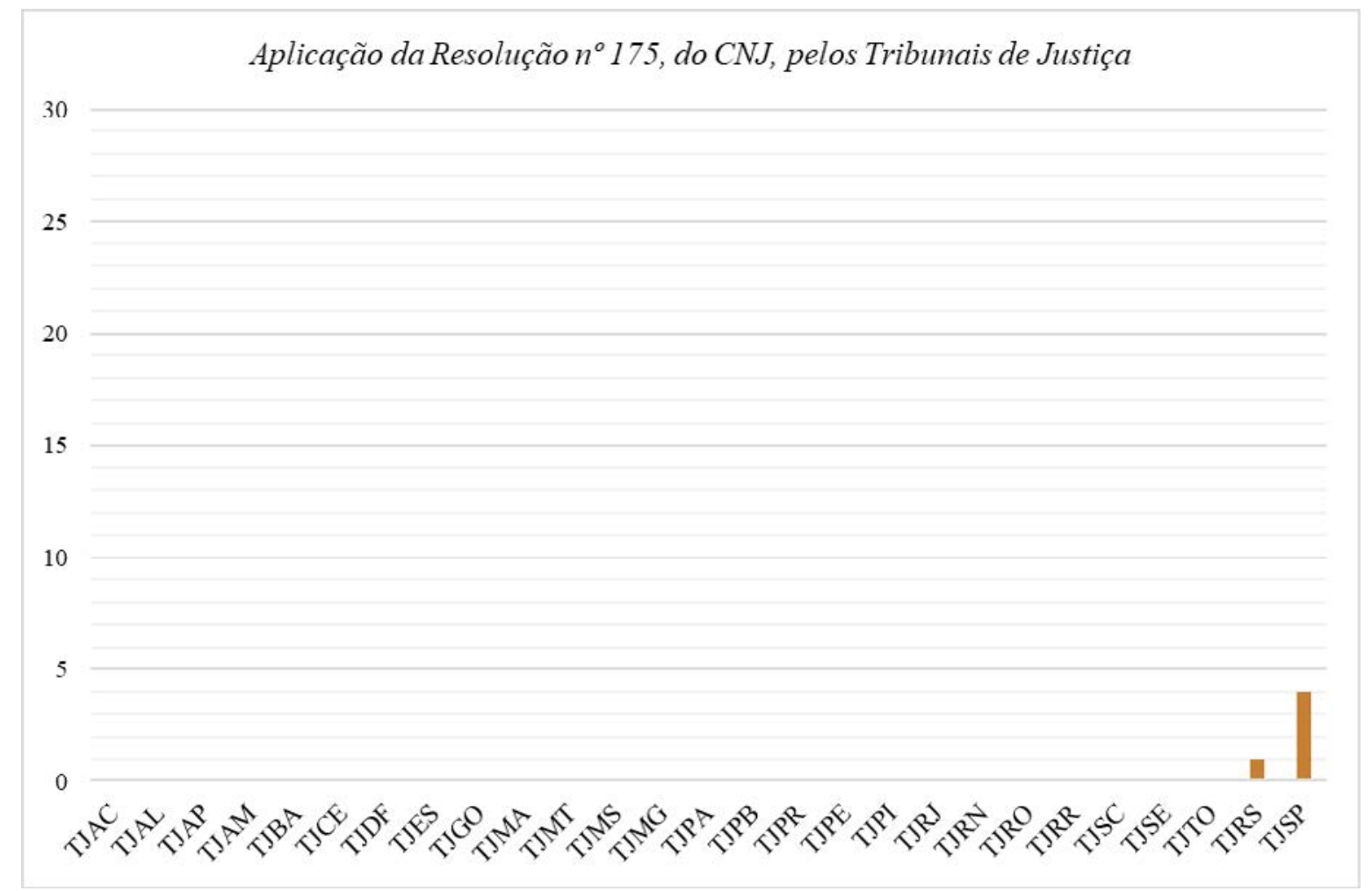

Fonte: elaborado pelas pesquisadoras

A coleta de dados, realizada a partir da utilização das palavras-chave "Resolução $n .^{\circ} 175^{\text {" e " }}$ "NJ", retornou apenas 05 (cinco) resultados em todos os Tribunais de Justiça nacionais. Apesar disso, representam, mais uma vez, situações em que o Poder Judiciário, instado a se manifestar acerca de um conflito, recorreu à aplicação de uma normativa exarada pelo CNJ.

Em relação à aplicação, pelos Tribunais, do disposto no Provimento n. ${ }^{\circ} 63 / 2017$, a pesquisa jurisprudencial dos termos "Provimento ${ }^{\circ}{ }^{\circ} 63$ " e "CNS" retornou 03 (três) resultados: um junto ao Tribunal de Justiça do Estado do Rio Grande do Sul e dois junto ao Tribunal de Justiça do Estado do Paraná.

Por fim, não foram localizados resultados com a utilização das palavras-chave "Provimento $n .^{\circ}$ 67" e "CNJ". É interessante destacar, no entanto, que a expedição desses dois últimos provimentos pelo Conselho Nacional de Justiça se deu, respectivamente, em 2017 e 2018, de modo que o questionamento sobre a sua aplicação perante o Poder Judiciário provavelmente passará a se tornar mais recorrente com o transcurso do tempo.

9 Considerando a possibilidade de que, por meio da utilização de palavras-chaves diversas, fossem obtidos mais resultados.

10 Exceto, mais uma vez, nas buscas efetuadas junto ao Tribunal de Justiça do Estado da Bahia e ao Tribunal de Justiça do Estado do Tocantins, uma vez que nesses Tribunais procedeu-se a um maior refinamento da busca, incluindo-se a palavra-chave "casamento". 


\section{Conclusão}

Diante do exposto ao longo do estudo ora apresentado, tem-se a resposta aos questionamentos propostos no início deste trabalho:

(i) Em que medida, e sob quais critérios, é possível a efetiva imposição de normas pelo CNJ, aptas a atingir particulares no ambiente do Direito Privado?

A constitucionalidade do Conselho Nacional de Justiça já foi objeto de análise pelo Supremo Tribunal Federal, que o reconheceu como entidade coberta de constitucionalidade na forma da Ação Direta de Inconstitucionalidade n. ${ }^{\circ}$ 3367-1/DF, movida pela Associação dos Magistrados Brasileiros (AMB). E, posteriormente, no julgamento da Ação Declaratória de Constitucionalidade $n .^{\circ} 12$, em que assegurou ser o CNJ órgão competente para expedições normativas vinculadas à densificação dos princípios constantes na Constituição "no que tange ao poder administrativo que detém no âmbito do Poder Judiciário" (BRASIL, ADC n. ${ }^{\circ}$ 12/DF, 2009, p. 15). Assim, além de constitucional, já teve competência normativa reconhecida no espectro do Poder Administrativo.

(ii) Seria o CNJ competente para gerar normas para o(a) cidadão(ã) comum?

Essa pergunta recebe uma resposta negativa apriorística, ou seja, em regra, o CNJ não tem competência para disciplinar questões direcionadas ao cidadão comum. Entretanto, considerada sua competência administrativa no ambiente notarial e registral, importa destacar que há, sim, materialidade para criação de direitos e obrigações aos particulares que procuram os serviços extrajudiciais. Portanto, ao se reconhecer a legitimidade constitucional do CNJ para regulamentar referidos serviços, acaba-se condicionando ao exercício de direitos (com ampliação ou restrição desses) no ambiente extrajudicial. Nesse contexto, uma questão que se coloca é a submissão dessas regulamentações à tutela de constitucionalidade material, ou seja, em ambiente de atuação administrativa, também à vinculação aos direitos fundamentais dos particulares envolvidos.

Apesar de a primariedade das normas expedidas pelo CNJ ter sido reconhecida no voto do ministro relator no julgamento da Medida Cautelar na ADC n. ${ }^{0} 12$, ainda assim é preciso afirmar a estrita vinculação material das normativas exaradas pelo Conselho à ordem constitucional.

Por fim, com relação às perguntas “(iii) Quais os limites à atuação normativa do CNJ?" e "(iv) Qual a força cogente das eventuais normativas expedidas pelo CNJ?", tem-se que os seguintes critérios podem ser elencados como parâmetros para controle da atuação do Conselho Nacional de Justiça em matérias atinentes ao Direito de Família:

3.1 Necessidade de que a disciplina emitida pelo CNJ encontre-se adstrita aos seus limites de competência, previstos no art. 103-B, $\S^{\circ}$ e inciso I, da CRFB/88; no art. $8^{\circ}$ do Regimento Interno do CNJ e no art. 14 do Regulamento Geral do CNJ.

3.2 Em havendo expedição de atos normativos de caráter geral e abstrato (conforme autorização do Supremo Tribunal Federal no âmbito da Medida Cautelar na ADC n. $\left.{ }^{0} 12-6 / D F\right)$, há necessidade de observância dos limites de competência anteriormente referidos, inclusive a fundamentalidade de direitos materialmente constitucionais, o que implica em vedação à restrição de direitos.

3.3 Quando diante de matéria em que há fonte normativa prévia, há necessidade de observância da fonte, sem inovação, uma vez que a análise primária já foi realizada pelo órgão originário.

3.4 E, estando diante de matéria em que não há fonte normativa prévia, atuação voltada à garantia dos direitos fundamentais constitucionalmente previstos, bem como da autonomia privada dos sujeitos.

Assim, tem-se que, em nenhuma medida, a primariedade das normas do $\mathrm{CNJ}$, assim reconhecida pelo STF, pode implicar na redução do núcleo constitutivo de fundamentalidade de cada um dos seres humanos

Compreendidas como "regulações capazes de obrigar", no sentido de permissões, vedações ou concessões. 
impactados pela norma. Trata-se de atuação normativa vinculada, não podendo disfarçar de legalidade a redução de direitos já consagrados, principalmente ao se tratar de exercício de autonomia privada.

\section{Referências}

BRANDELLI, Leonardo. Teoria geral do direito notarial. 3. ed. São Paulo: Saraiva, 2009.

BRASIL. Conselho Nacional de Justiça. Pedido de providências $n^{\circ}$ 0001459-08.2016.2.00.0000.

Pedido de providências. União estável poliafetiva. Entidade familiar. Reconhecimento. Impossibilidade.

Família. Categoria sociocultural. Imaturidade social da união poliafetiva como família. Declaração de vontade. Inaptidão para criar ente social. Monogamia. Elemento estrutural da sociedade.

Escritura pública declaratória de união poliafetiva. Lavratura. Vedação. Relator: Min. João Otávio de Noronha, 29 de junho de 2018. Disponível em: https://www.jota.info/wp-content/uploads/2018/08/ a76994fe42703dab2c66aad9f04c56a9.pdf?x48657. Acesso em: 08 jan. 2019.

BRASIL. Conselho Nacional de Justiça. Provimento ${ }^{\circ}$ 63, de 14 de novembro de 2017. Institui modelos únicos de certidão de nascimento, de casamento e de óbito, a serem adotadas pelos ofícios de registro civil das pessoas naturais, e dispõe sobre o reconhecimento voluntário e a averbação da paternidade e maternidade socioafetiva no Livro "A" e sobre o registro de nascimento e emissão da respectiva certidão dos filhos havidos por reprodução assistida. Brasília, DF: CNJ, 2017. Disponível em: http://www.cnj.jus.br/busca-atos-adm?documento=3380. Acesso em: 08 jan. 2019.

BRASIL. Conselho Nacional de Justiça. Provimento $n^{\circ}$ 67, de 26 de março de 2018. Dispõe sobre os procedimentos de conciliação e de mediação nos serviços notariais e de registro do Brasil. Brasília, DF: CNJ, 2018. Disponível em: http://www.cnj.jus.br/busca-atos-adm?documento=3415. Acesso em: 08 jan. 2019.

BRASIL. Conselho Nacional de Justiça. Provimento n 83, de 14 de agosto de 2019. Altera a seção II, que trata da paternidade socioafetiva, do provimento n. 63, de 14 de novembro de 2017 da Corregedoria Nacional de Justiça. Brasília, DF: CNJ, 2019. Disponível em: http://www.recivil.com.br/noticias/noticias/ view/cnj-publica-provimento-n-83-que-altera-requisitos-na-paternidade-socioafetiva.html. Acesso em: 04 out. 2019.

BRASIL. Conselho Nacional de Justiça. Regimento Interno do Conselho Nacional de Justiça.

Brasília, DF: CNJ, 2015. Disponível em: http://www.cnj.jus.br/files/conteudo/arquivo/2015/10/ b8953e0554207c0f4fb95a29e9326532.pdf. Acesso em: 24 dez. 2018.

BRASIL. Conselho Nacional de Justiça. Regulamento Geral da Corregedoria Nacional de Justiça. Brasília, DF: CNJ, 2012. Disponível em: http://www.cnj.jus.br/corregedoriacnj/regulamento-geral. Acesso em: 24 dez. 2018.

BRASIL. Conselho Nacional de Justiça. Resolução $n^{\circ}$ 07, de 18 de outubro de 2005. Disciplina o exercício de cargos, empregos e funções por parentes, cônjuges e companheiros de magistrados e de servidores investidos em cargos de direção e assessoramento, no âmbito dos órgãos do Poder Judiciário e dá outras providências, Brasília, DF: CNJ, 2005. Disponível em: https://atos.cnj.jus.br/atos/ detalhar/187. Acesso em 04 jan. 2019.

BRASIL. Conselho Nacional de Justiça. Resolução $n^{\circ} 175$, de 14/05/2013. Dispõe sobre a habilitação, celebração de casamento civil, ou de conversão de união estável em casamento, entre pessoas de mesmo sexo., Brasília, DF: CNJ, 2013. Disponível em: http://www.cnj.jus.br/busca-atosadm?documento=2504. Acesso em 08 jan. 2019.

BRASIL. Supremo Tribunal Federal, Medida Cautelar em Mandado de Segurança ${ }^{\circ}$ 32.077/DF. Relator: Min. Luiz Fux, 28 de maio de 2013. Disponível em: http://www.stf.jus.br/portal/processo/ verProcessoPeca.asp?id=143964315\&tipoApp=.pdf. Acesso em: 17 jun. 2020.

BRASIL. Supremo Tribunal Federal. Ação Declaratória de Constitucionalidade $n^{\circ}$ 12/DF, de 18 de dezembro de 2009. Relator: Min. Carlos Britto, 20 de agosto de 2008. Disponível em: http://redir.stf.jus. br/paginadorpub/paginador.jsp?docTP=AC\&doclD=606840. Acesso em: 17 jun. 2020. 
BRASIL. Supremo Tribunal Federal. Ação Direta de Inconstitucionalidade $\mathbf{n}^{\circ}$ 3.367-1/DF, de 17 de março de 2006. Relator: Min. Cezar Peluso, 13 de abril de 2005. Disponível em: http://redir.stf.jus.br/ paginadorpub/paginador.jsp?docTP=AC\&docID=363371. Acesso em: 17 jun. 2020.

BRASIL. Supremo Tribunal Federal. Medida Cautelar na ADC n 12-6/DF, de 01 de setembro de 2006. Relator: Min. Carlos Britto, 16 de fevereiro de 2006. Disponível em: http://redir.stf.jus.br/paginadorpub/ paginador.jsp?docTP=AC\&docID=372910. Acesso em: 17 jun. 2020.

CARDOSO, Simone Tassinari. Do contrato parental à socioafetividade. In: ARONNE, Ricardo (org.). Estudos de direito civil-constitucional. Porto Alegre: Livraria do Advogado, 2004. p. 19-110.

FARIAS, Cristiano Chaves de; ROSENVALD, Nelson. Curso de direito civil: Famílias. 10. ed. rev. e atual. Salvador: JusPodivm, 2018.

KÜMPEL, Vitor Frederico. A efetivação do Direito por meio da atividade tabelioa e registral. Migalhas, São Paulo, 07 maio 2013. Disponível em: https://www.migalhas.com.br/Registralhas/98,Ml177770,91041A+efetivacao+do+Direito+por+meio+da+atividade+tabelioa+e+registral. Acesso em: 17 jan. 2019.

KÜMPEL, Vitor Frederico; BORGARELLI, Bruno de Ávila. Provimento reaviva debate sobre limites do CNJ em serventias extrajudiciais. Consultor Jurídico, São Paulo, 29 jan. 2018. Disponível em: https:// www.conjur.com.br/2018-jan-29/direito-civil-atual-provimento-reaviva-debate-limites-cnj-cartorios. Acesso em: 31 ago. 2018.

MAFFINI, Rafael. Regulação da função notarial e registral e os limites normativos do Poder Judiciário.

Revista de Direito Imobiliário, São Paulo, v. 79, n. 2, p. 179-202, jul./dez. 2015.

MEIRELLES, Hely Lopes; BURLE FILHO, José Emmanuel. Direito administrativo brasileiro. 42. ed. São Paulo: Malheiros, 2016.

NOGUEIRA, Roberto Wagner Lima. Resolução do CNJ e lei são atos normativos primários. Consultor Jurídico, São Paulo, 21 fev. 2006. Disponível em: https://www.conjur.com.br/2006-fev-21/resolucao_cnj_ lei_sao_atos_normativos_primarios. Acesso em: 17 jan. 2019.

PERLINGIERI, Pietro. Perfis do direito civil: introdução ao direito civil constitucional. Tradução de Maria Cristina De Cicco. 3. ed. rev. e ampl. Rio de Janeiro: Renovar, 2002.

SILVEIRA, Denise Tolfo; CÓRDOVA, Fernanda Peixoto. A pesquisa científica. In: GERHARDT, Tatiana Engel; SILVEIRA, Denise Tolfo (org.). Métodos de pesquisa. Porto Alegre: Editora da UFRGS, 2009. p. 31-42.

SOARES, R. Ehrardt. Princípio da legalidade e administração constitutiva. Boletim da Faculdade de Direito da Universidade de Coimbra, Coimbra, v. 57, p. 169-192, 1981. Disponível em: https:// heinonline.org/HOL/P?h=hein.journals/boltfdiuc57\&i=177. Acesso em: 17 jan. 2019.

STRECK, Lenio Luiz; SARLET, Ingo Wolfgang; CLĖVE, Clèmerson Merlin. Os limites constitucionais das resoluções do Conselho Nacional de Justiça (CNJ) e Conselho Nacional do Ministério Público (CNMP). Migalhas, São Paulo, 16 jan. 2006. Disponível em: https://www.migalhas.com.br/ dePeso/16,MI20381,41046-Os+limites+Constitucionais+das+resolucoes+do+Conselho+Nacional+de. Acesso em: 31 ago. 2018.

TEPEDINO, Gustavo. O Direito Civil-Constitucional e suas perspectivas atuais. In: Direito civil contemporâneo: novos problemas à luz da legalidade constitucional (Anais do Congresso Internacional de Direito Civil-Constitucional da Cidade do Rio de Janeiro, 2006). São Paulo: Atlas, 2008. p. 356-371.

TRINDADE, André Karam; MORAIS, Fausto Santos de. Ativismo judicial: as experiências norteamericana, alemã e brasileira. Revista da Faculdade de Direito UFPR, Curitiba, v. 53, p. 137-54, 2011. 